\title{
A life-cycle cost analysis for flooring materials for healthcare facilities
}

\author{
Debra D. Harris ${ }^{* 1}$, Lori Fitzgerald ${ }^{2}$ \\ ${ }^{1}$ RAD Consultants, Inc., Austin, Texas, USA \\ ${ }^{2}$ Fitzgerald Consulting, Austin, Texas, USA
}

Received: March 19, 2015

DOI: $10.5430 /$ jha.v4n4p92
Accepted: May 13, 2015

URL: http://dx.doi.org/10.5430/jha.v4n4p92

\begin{abstract}
Objective: In this study, hard, resilient and soft flooring materials are compared using a building service life of 50 years, an established life span for healthcare facilities. The purpose of this study is to evaluate the life-cycle cost of flooring products and inform decision-makers about the long-term cost of ownership along with other key factors, such as safety, durability, and aesthetics.

Methods: The protocol for executing an life-cycle cost analysis (LCCA) is defined by the National Institute of Standards and Technology (NIST), including defining the problem, identifying feasible alternatives, and establishing common assumptions and parameters, as well as acquiring financial information. Product information for the flooring materials that met inclusion criteria based on characteristics of the products consistent with use in healthcare facilities was acquired including maintenance, installation, warranty, and cost data. LCCA calculations recognize the time value of money and use discounting to project future value.

Results: The results generated from the LCCA using present value to project future costs provide a useful tool for projecting costs over time for the purpose of planning operational and maintenance costs associated with the long-term investment of ownership. The findings suggest that soft flooring is more cost effective for initial purchase and installation, equipment assets, and maintenance over time of facilities.

Conclusions: Cost is an important factor when considering flooring materials for healthcare facilities. Other factors to be considered are safety, durability and aesthetics, cleanliness, acoustics and sustainability to realize the overall return on investment. This study developed a tool for projecting costs of ownership for facility materials, in this case, flooring. The selection of flooring material has a significant impact on the cost of ownership over the life of the facility.
\end{abstract}

Key Words: Life-cycle cost analysis, Flooring materials, Hospital, Healthcare facility, Facility management, Asset management

\section{INTRODUCTION}

The selection of flooring material for healthcare facilities requires consideration of multiple factors including influences on the occupant outcomes, safety, aesthetics, durability, maintenance, and costs. Budget constraints often limit the selection of materials, but are also influenced by manu- facturer's information, personal experience, or may solely be driven by the product's initial cost. ${ }^{[1]}$ In this study, hard, resilient and soft flooring materials are compared using a building service life of 50 years, an established life span for hospitals. The purpose of this study is to evaluate the lifecycle cost of flooring products and inform decision-makers

*Correspondence: Debra D. Harris; Email: debra@rad-consultants.com; Address: 3911 Greystone Dr., Austin, TX 78731, USA. 
about the long-term cost of ownership.

According to a survey conducted by the American College of Healthcare Executives, the current financial climate, including reimbursement challenges and government mandates, produces an environment where healthcare systems have to do more with less. ${ }^{[2]}$ Despite financial limitations, hospital administrators are challenged with continuing to ensure patient safety and quality of care, suggesting that operational budgeting is paramount to managing a successful organization. Flooring is a major component of any hospital facility. Operations and maintenance (O\&M) of floors are expensive as a result of frequently scheduled cleaning protocols, along with periodic repair and replacement. Spills, heavy foot, equipment and gurney traffic contribute to the necessity for continued investment. Understanding life-cycle cost analysis (LCCA) of flooring will provide administrators with the information needed to plan for the long-term cost of ownership.

Emerging and established research shows that the physical design characteristics of the hospital environment can have a meaningful impact on occupant (patients, visitors, and staff) outcomes. In a comprehensive literature review of more than 600 studies, researchers found that material and design features that improve ergonomics, promote privacy, reduce noise, and improve lighting contribute to patient safety, reduce patient and staff stress and fatigue, and increase overall healthcare quality. ${ }^{[3]}$ In addition to looking at initial and long-term costs of flooring materials, other factors, such as infection control, durability, safety, noise and comfort underfoot are considerations when choosing a flooring material.

One area of evidenced-based design that impacts occupant safety is flooring material choice. A literature review that studied the impact of flooring on patient and healthcare worker safety found a relationship between flooring and safety. Of note was the research showing a relationship between flooring and hospital acquired infections; injuryrelated issues, such as falls, stressors, and noise; and fatigue. Based on the literature, designing for safety and quality offsets the investment with improved outcomes for occupants; and flooring is an important design decision for achieving those goals. ${ }^{[4]}$

LCCA refers to a method that evaluates the total cost of ownership of an asset (or building system) throughout its expected life. In the building industry, LCCA represents a departure from traditional decision-making which focuses on initial capital cost alone. LCCA evaluates the life-cycle cost of a building or building system and compares it to that of functionally equivalent alternatives. ${ }^{[5]}$ LCCA considers all relevant costs over a designated study period. ${ }^{[6,7]}$ The protocol for executing an LCCA is defined by the National Institute of Standards and Technology (NIST), including defining the problem, identifying feasible alternatives, and establishing common assumptions and parameters as well as acquiring financial information. ${ }^{[8]}$

The practice of applying LCCA gained prominence in the 1960s when US government agencies sought to improve the cost effectiveness of equipment procurement. The Department of Defense (DoD) found that the initial cost of weapons systems were a fraction of the total cost of ownership. ${ }^{[9]}$ The DoD determined that operations and support costs of weapons systems were $70 \%$ of the total cost of ownership.

Since then, the use of LCCA has spread throughout a number of both private and public industries with an extensive body of literature published on the topic. LCCA is commonly utilized in road construction, as a key component in making long-term economic decisions between competing options during the design and maintenance of infrastructures, including pavements, bridges, and highways. ${ }^{[10-12]}$ LCCA has also been applied to energy conservation, ${ }^{[5]}$ the total cost of buildings and building systems, ${ }^{[13]}$ and product development, ${ }^{[14]}$ among others.

Publications on LCCA for flooring are limited. Two studies concluded that the most economical initial cost did not result in the lowest life cycle cost over time for most flooring systems. ${ }^{[15,16]}$ Moussatche and Languell ${ }^{[16]}$ conducted a study looking at three categories (hard, resilient and soft) of commonly used interior flooring systems within the State of Florida K-12 facilities. They concluded that flooring materials with the lowest initial costs (epoxy and VCT) in the hard and resilient categories did not prove to be the lowest cost alternatives when applying LCCA to these flooring materials. Alternatively, their results showed that carpet tile in the soft flooring category had the lowest initial cost and lowest service life cost overall.

\section{METHOdS}

\subsection{Data collection}

Primary data collection focused on identifying typical flooring materials specified for healthcare facilities that met performance, maintenance, and safety criteria based on industry standards, as defined by the Facilities Guidelines Institute Guidelines for the Design and Construction of Hospitals and Outpatient Facilities (2014). ${ }^{[17]}$ With regard to performance and safety, flame spread is of primary concern. Interior floor finish and floor covering materials in healthcare environments must be Class I or Class II in accordance with NFPA 253. The classifications determined by NFPA 253 are as follows: Class I (0.45 watts $/ \mathrm{cm}^{2}$ or greater); and Class II 
(0.22 watts $/ \mathrm{cm}^{2}$ or greater). Specific to healthcare are concerns related to the transmission of pathogens increasing risk of infection of patients and healthcare workers. OSHA requires that work surfaces be cleaned with an "appropriate disinfectants" to provide clean and sanitary work environments to prevent contact with blood or OPIM (Bloodborne Pathogens Standard [29 CFR 1910.1030(d)(4)(i)]). Appropriate disinfectants include a diluted bleach solution (10\%) and EPA-registered antimicrobial products such as tuberculocides, sterilants, and products registered against HIV/HBV, and sterilants/high level disinfectants for equipment sterilization. Fresh solutions of diluted household bleach made up every 24 hours are also considered appropriate for disinfection of environmental surfaces and for decontamination of sites. Contact time for bleach is generally considered to be the time it takes the product to air dry. One of the primary risks for patients and healthcare workers in the healthcare environment is the risk of falling. Flooring finish materials appropriate for healthcare environments should minimize the risk of falling from slipping on the floor. The standard, ASTM D-2047 (UL-410) is used to determine the coefficient of friction (cof). Floor materials with a coefficient of friction (cof) of 0.5 or greater met the inclusion criteria for safety. Floor materials that met all of the criteria listed herein were included in the LCCA analysis.

Product information for the flooring materials that met inclusion criteria based on characteristics of the products consistent with use in healthcare facilities was acquired including: maintenance protocols, installation instructions, warranties, cleaning equipment specifications and warranties, and cost data. Cost data for material, installation, equipment, and O\&M were acquired from R.S. Means Cost Estimating database ${ }^{[18]}$ R.S. Means is North America's leading supplier of construction cost information, providing accurate and up-to-date cost information that helps owners, developers, architects, engineers, contractors and others to project carefully and precisely and control the cost of both new building construction and renovation projects. Material and installation costs were verified in the field. This study evaluated three categories of flooring including hard, resilient, and soft flooring. O\&M costs play a major role in the long-term cost of ownership. Routine cleaning protocols feature largely in those expenditures. Clearly identifying maintenance procedures for each type of flooring is essential in using the LCCA tool to compare floor material alternatives (see Table 1).

\subsection{Data analysis}

\subsubsection{Assumptions and parameters} standards set by NIST and the Department of Energy (DOE).
The assumptions and parameters for the LCCA are based on

Product selections were based on typically specified products for healthcare. All analyses except for equipment costs are based on square foot (SF) cost.

Discount rate. With every project, there are initial costs and future costs. The initial costs include direct costs of labor and materials for installation, along with overhead and profit. Future costs are all the costs incurred after product installation is complete, such as maintenance and repair, replacement, and demolition costs for the service life of the building. Because these costs will occur in the future and the value of a dollar today is less than the value of that same dollar in the future, a discount rate, reflecting the cost of capital, is applied to the future costs to equate them with present day costs. ${ }^{[22,23]}$ The discount rate used for this LCCA is a weighted average cost of capital, defined as the prime interest rate $(3.25 \%)$ plus $1 \%$ for a total of $4.25 \%$.

Building and systems service life. The building service life for healthcare is 50 years. The service life for each system (flooring material) alternative was determined by the warranty information. The number of replacements was based on each system's service life over a 50 year life span. For example, if a system's (or floor's) warranty was 10 years, then the cost of five replacements was accounted for (at years 10, 20, 30, 40 and 50) over the building's 50 year life span.

Salvage value. It is assumed that the entire cost of each system alternative has depreciated over the system's useful life, with no salvage value at the time of replacement.

Flooring. For the purpose of this LCCA, all flooring will be considered subject to heavy traffic for an equivalent comparison.

Initial costs. Initial costs included flooring material costs, labor and materials for installation, floor preparation and initial cleaning, and overhead and profit. Based on cost per SF, the equation is (see Equation 1):

$$
M+L+O \& P=\text { Total Initial Cost }
$$

where $\mathrm{M}=$ material cost, $\mathrm{L}=$ labor (installation) cost, and $\mathrm{O} \& \mathrm{P}=$ overhead and profit.

O\&M costs. O\&M costs are all future costs including floor material replacement (including demolition/removal cost) and maintenance. The number of replacements was determined by product warranties and industry standards. The formula for replacement costs is Equation 2:

$$
M+L+D+O \& P=\text { Replacement Cost }
$$

where $\mathrm{M}=$ material cost, $\mathrm{L}=$ labor cost, $\mathrm{D}=$ demolition 
cost, and $\mathrm{O} \& \mathrm{P}=$ overhead and profit. Cost of maintenance includes standard operating procedures for performance (labor), chemical cleaning materials and, in the case of hard surface flooring, it includes regrouting if appropriate. Using the discount rate of $4.25 \%$ over a 50 -year timeline, the future value was calculated to determine the cost of replacements, based on the system service life, and maintenance, expressed as FV (future value) of PV (present value) dollars.

Table 1. Floor care maintenance procedures for heavy traffic

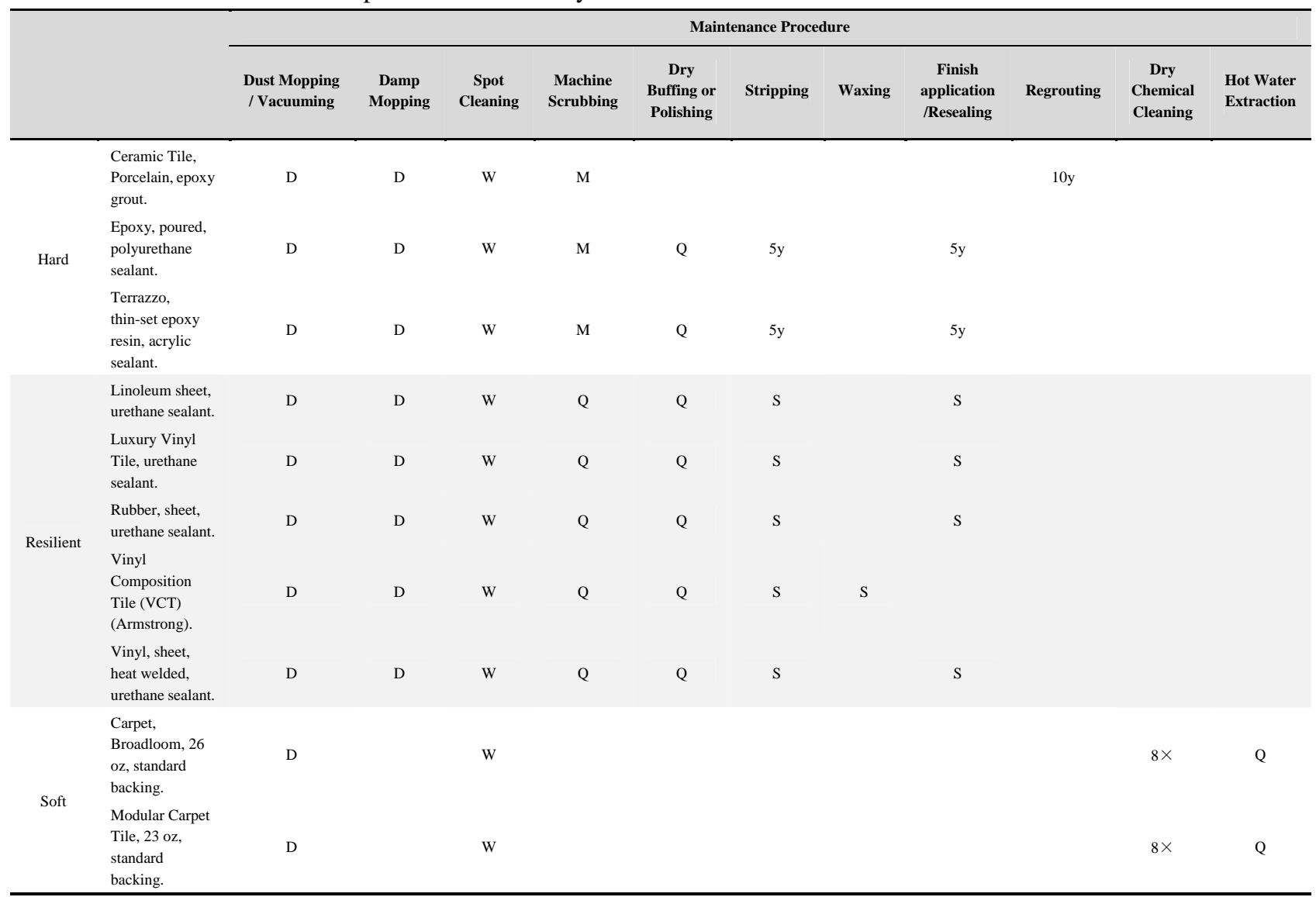

Note: $\mathrm{D}=$ Daily; $\mathrm{W}=$ Weekly $; \mathrm{M}=$ Monthly; $\mathrm{Q}=$ Quarterly; $\mathrm{S}=$ Semiannually; $5 \mathrm{y}=$ Every 5 years; $10 \mathrm{y}=$ Every 10 years; $8 \times=8$ times per year; Maintenance, asset service life, and cost data were acquired from the following sources. ${ }^{[15,16,18-21]}$

Other cost considerations are initial cost of equipment, equipment maintenance, and equipment replacements. Using the discount rate of $4.25 \%$, FV was projected over the 50 year life of the building based on initial and replacement costs of cleaning equipment. Cost of equipment is included in the LCCA as costs over time based on warranty and expected life of the product.

LCCA computations and comparisons. LCCA computations begin with the cash flow diagram, so that the long-term costs and benefits associated with the fulfillment of specific needs are quantified and captured, as shown in Figure 1. LCCA calculations recognize the time value of money and use discounting-at a Minimally Attractive Rate of Return to bring all cash flows to an identical point in time and so ensure "apples to apples comparisons" of all cumulative cash flows. The algorithm used for this analysis is based on PV analysis to determine the $\mathrm{FV}$ of costs.

\section{RESULTS}

The results from this LCCA are intended to present a quantitative assessment tool and an analysis of flooring material alternatives to inform decision makers about flooring materials where the comprehensive cost of the material over the service life of the building is a factor in selection. Appropriate flooring materials that meet aesthetics, performance, and O\&M requirements may be evaluated based on life-cycle costs as a factor for determining the best solution for healthcare facilities.

\subsection{Initial costs}

The initial costs of flooring include material cost, labor for installation, overhead and profit for a total cost per SF in PV dollars (see Table 2). The lowest initial cost for all flooring 
was vinyl composition tile (VCT) and soft flooring. Terrazzo and rubber were the most expensive. When averaged by category, the overall initial cost for hard surface flooring was $\$ 9.72 / \mathrm{SF}$; resilient surface flooring was $\$ 6.36 / \mathrm{SF}$; and soft surface flooring was $\$ 3.69$. The table also features the system service life in years for each material based on manufacturers' warranties. Ceramic tile and terrazzo flooring will require one replacement during a 50 year building life cycle, whereas the other flooring options will require multiple replacements.

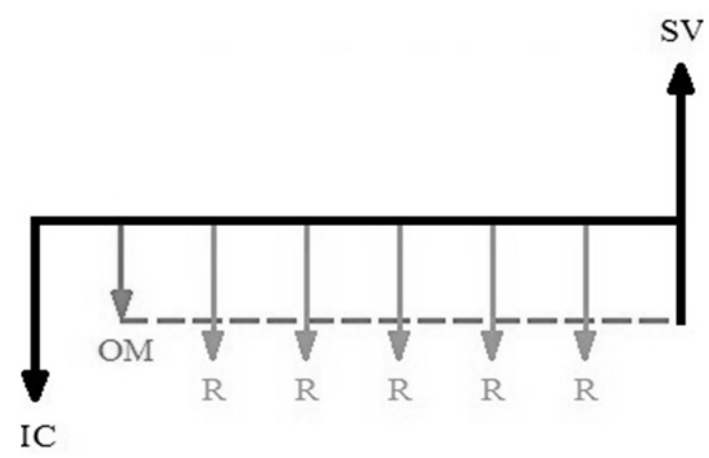

Figure 1. Cash flow diagram used to recognize the long-term costs associated with ownership of a capital investment

\subsection{Equipment costs}

Initial equipment and supply costs are outlined in Table 3, along with the system service life for each. Equipment costs were identical for hard and resilient flooring, reflecting the similar O\&M processes and the equipment required for pro- viding maintenance of these floor types. Total initial equipment and supply costs are almost 2.5 times more expensive for hard and resilient flooring than for soft flooring.

Figure 2 shows cumulative costs over time per SF beginning with the initial purchase of equipment and supplies in year 1, along with the costs of equipment supplies and equipment replacements, if appropriate, at years 10, and 25. Accordingly, the 10 year total cost for the equipment and equipment supplies was just over $\$ 30,000$ for hard and resilient flooring and just over $\$ 12,000$ for soft flooring. When extrapolating these costs beyond year 25 up to year 50, the total cost reaches over $\$ 300,000$ for hard and resilient flooring and just over \$121,000 for soft flooring. All dollar amounts, except for year 1 (PV), represent the future value of dollars.

\subsection{O\&M}

The annual cost per SF for O\&M increases over time from PV to FV calculated using the discount rate (see Figure 3). Each material type shows variation in cost per SF depending on year of material replacements. For example, at year 10 , flooring replacements are required for luxury vinyl tile (LVT), rubber, and broadloom carpet; these replacement costs are accounted for and recorded at their respective future values, hence the greater jump in cost for these materials when compared to the others. At year 20, LVT, rubber, and broadloom carpet are replaced again and are accounted for in year 25. Year 25 also reflects flooring replacements for epoxy, linoleum sheet, VCT, vinyl sheet, and modular carpet tile (MCT). O\&M costs reflect heavy traffic use and include material demolition and replacements, per manufacturers' warranties, and all recommended maintenance as represented in Table 1.

Table 2. Initial costs of hard, resilient, and soft flooring

\begin{tabular}{|c|c|c|c|c|c|c|c|}
\hline \multicolumn{2}{|c|}{ Material Type } & \multirow{2}{*}{$\begin{array}{l}\text { System Service } \\
\text { Life Years } \\
50\end{array}$} & \multirow{2}{*}{$\begin{array}{l}\text { Unit } \\
\text { SF }\end{array}$} & \multirow{2}{*}{$\begin{array}{l}\text { Material Cost } \\
\$ 5.20\end{array}$} & \multirow{2}{*}{$\begin{array}{c}\text { Install Cost } \\
\$ 2.57\end{array}$} & \multirow{2}{*}{$\begin{array}{l}\text { O\&P } \\
\$ 2.07\end{array}$} & \multirow{2}{*}{$\begin{array}{l}\begin{array}{l}\text { Total Initial } \\
\text { Cost/SF (PV) }\end{array} \\
\$ 9.84\end{array}$} \\
\hline \multirow{3}{*}{ Hard } & Ceramic Tile, Porcelain, epoxy grout & & & & & & \\
\hline & Epoxy, poured, polyurethane sealant & 15 & SF & $\$ 2.75$ & $\$ 2.20$ & $\$ 1.70$ & $\$ 6.65$ \\
\hline & Terrazzo, thin-set epoxy resin, acrylic sealant & 40 & SF & $\$ 5.85$ & $\$ 4.39$ & $\$ 2.44$ & $\$ 12.68$ \\
\hline \multirow{5}{*}{ Resilient } & Linoleum sheet, urethane sealant & 20 & SF & $\$ 3.59$ & $\$ 0.73$ & $\$ 0.80$ & $\$ 5.12$ \\
\hline & Luxury Vinyl Tile, urethane sealant & 10 & SF & $\$ 2.50$ & $\$ 0.84$ & $\$ 3.06$ & $\$ 6.40$ \\
\hline & Rubber, sheet, urethane sealant & 10 & SF & $\$ 6.45$ & $\$ 2.91$ & $\$ 1.14$ & $\$ 10.50$ \\
\hline & Vinyl Composition Tile (VCT) (Armstrong) & 20 & SF & $\$ 2.21$ & $\$ 0.52$ & $\$ 0.55$ & $\$ 3.28$ \\
\hline & Vinyl, sheet, heat welded, urethane sealant & 15 & SF & $\$ 4.25$ & $\$ 1.14$ & $\$ 1.13$ & $\$ 6.52$ \\
\hline \multirow{2}{*}{ Soft } & Carpet, Broadloom, 26 oz, standard backing & 10 & SF & $\$ 2.77$ & $\$ 0.39$ & $\$ 0.57$ & $\$ 3.73$ \\
\hline & Modular Carpet Tile, 23 oz, standard backing & 15 & SF & $\$ 2.78$ & $\$ 0.36$ & $\$ 0.50$ & $\$ 3.64$ \\
\hline
\end{tabular}

When comparing total costs per SF by category for maintenance (labor and cleaning materials costs only) at years 1 , 10, and 25, costs increased over time (see Figure 4). When assessing cumulative maintenance costs alone, hard and re96 silient flooring cost about 6 times more than for soft flooring. This same difference continues throughout the life of the building. 
Table 3. Initial equipment and supply costs

\begin{tabular}{|c|c|c|c|c|c|c|}
\hline Material & Description & Unit & $\begin{array}{l}\text { System Service } \\
\text { Life Years }\end{array}$ & Equipment Cost & O\&P & Total \\
\hline \multirow{8}{*}{$\begin{array}{l}\text { Hard \& } \\
\text { Resilient }\end{array}$} & 24 oz heavy duty microfiber mop w bucket & ea & 5 & $\$ 123.63$ & $\$ 34.87$ & $\$ 158.50$ \\
\hline & Dust mop 24" (2) & ea & 1 & $\$ 23.40$ & $\$ 6.60$ & $\$ 30.00$ \\
\hline & Damp mop, microfiber (2) & ea & 1 & $\$ 19.11$ & $\$ 5.39$ & $\$ 24.50$ \\
\hline & Spot cleaning, machine & ea & 8 & $\$ 517.14$ & $\$ 145.86$ & $\$ 663.00$ \\
\hline & Finish applicator, 18" flat mop incl. & ea & 5 & $\$ 255.65$ & $\$ 72.11$ & $\$ 327.76$ \\
\hline & Finish applicator replacement mops (6) & ea & 1 & $\$ 73.64$ & $\$ 20.77$ & $\$ 94.41$ \\
\hline & 20" self-propelled auto scrubber w/ supplies & ea & 10 & $\$ 4,877.56$ & $\$ 1,375.72$ & $\$ 6,253.28$ \\
\hline & 20" 1.5 hp Floor Machine - buffer/polisher & ea & 10 & $\$ 1,639.90$ & $\$ 462.54$ & $\$ 2,102.44$ \\
\hline \multicolumn{6}{|c|}{ Hard \& Resilient Flooring Equipment Total } & $\$ 9,653.89$ \\
\hline \multirow{4}{*}{ Soft } & Dual motor vacuum 18 " brush & ea & 5 & $\$ 396.84$ & \$87.11 & $\$ 483.95$ \\
\hline & Hot water extractor 5 ' wand, 12 " head & ea & 5 & $\$ 1,019.00$ & $\$ 380.00$ & $\$ 1,399.00$ \\
\hline & Dry foam soil extractor $24 "$ brush & ea & 8 & $\$ 1,240.00$ & $\$ 260.00$ & $\$ 1,500.00$ \\
\hline & EZ spot extractor w/ heat, $804 \mathrm{~W}$ motor & ea & 5 & $\$ 397.93$ & $\$ 112.24$ & $\$ 510.17$ \\
\hline \multicolumn{6}{|c|}{ Soft Flooring Equipment Total } & $\$ 3,893.12$ \\
\hline
\end{tabular}

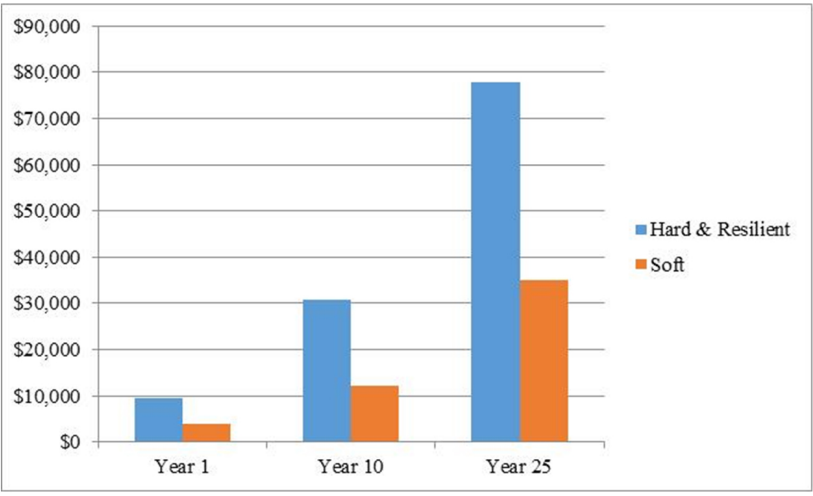

Figure 2. Cumulative equipment costs at Years 1, 10, and 25 based on present and future values

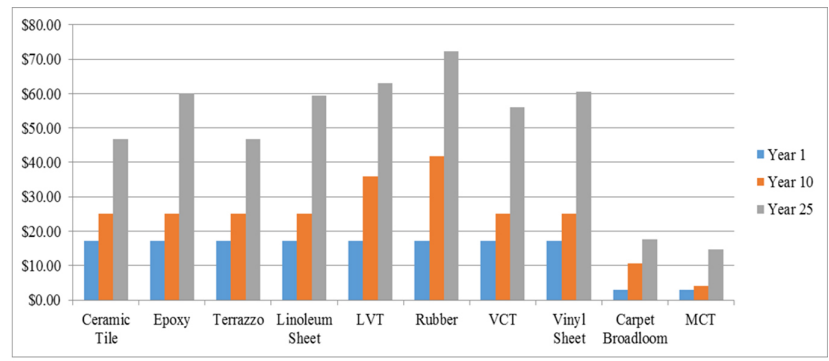

Figure 3. Annual maintenance and material replacement costs per SF at years 1, 10, and 25 based on present and future values

Using the PV and the discount rate to determine FV, the cumulative costs to maintain the floors in a 250,000 SF facility, typical of an American general hospital (U.S. DOE, 2014), are presented in Figure 5. The maintenance only (labor and cleaning material) costs increased by approximately 12 -fold between year 1 and year 10. Additionally, the maintenance

Published by Sciedu Press only costs for hard and resilient flooring are about 6 times greater for hard and resilient floors when compared to soft flooring. This 6-fold difference continues throughout the life of the building.

\section{Discussion}

The initial costs for materials and installation of hard, resilient, and soft flooring were expected. The cost data were based on national averages and does not specifically account for special pricing provided by purchasing agreements. Terrazzo and rubber had the highest cost per SF with VCT and soft flooring lowest in cost. In the resilient category, rubber was substantially more costly than other resilient flooring, while VCT costs the least and was more comparable to the cost of soft flooring. When considering initial costs (installed costs), the average costs for hard surfaces were higher than the resilient; and the resilient was higher than the soft flooring.

Flooring system service life can be an important factor in healthcare, since shutting down a unit can interfere with the daily operations of building occupants. However, the time required to replace flooring is dependent on the type of flooring and required processes and materials. For instance, when considering resilient flooring materials, rubber, because of its shorter service life was the most expensive flooring to maintain when compared to vinyl sheet, VCT, linoleum, and LVT. Terrazzo, the most expensive material for initial costs, is expensive to maintain. However, because of its long 40 year system service life, it is not the most expensive flooring over time. 


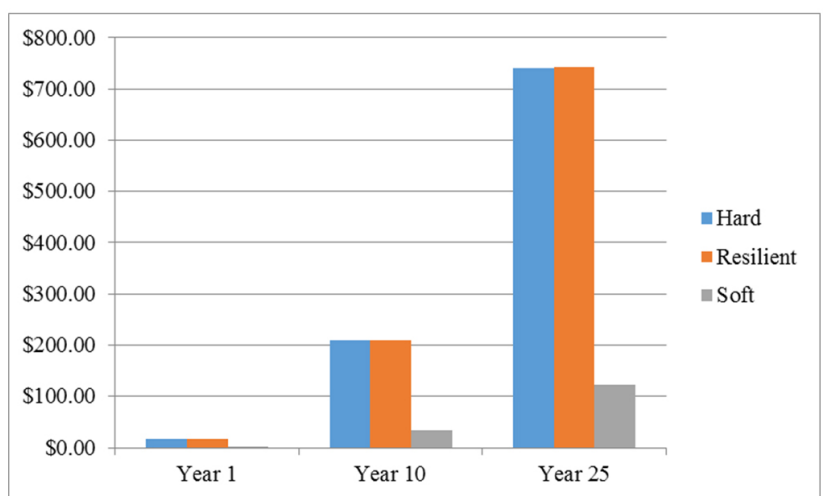

Figure 4. Cumulative maintenance (labor and cleaning materials) costs per SF at Years 1, 10, and 25 based on present and future values

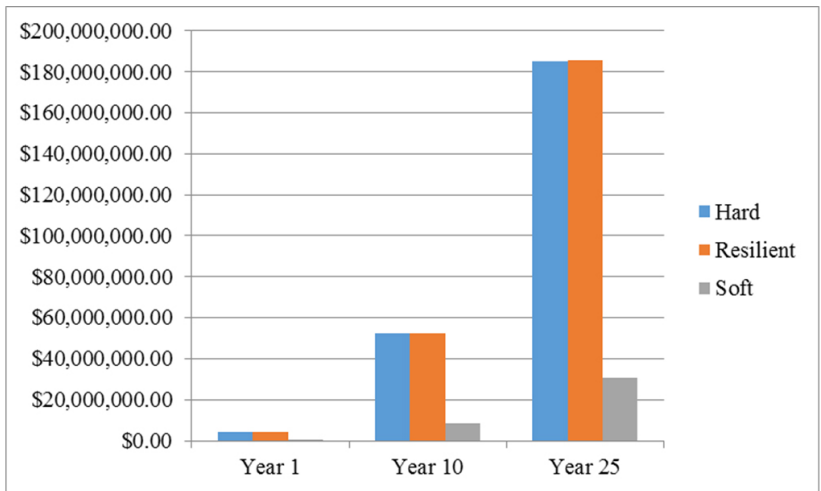

Figure 5. Cumulative maintenance (labor and cleaning materials) costs for a 250,000 SF building based on present and future values

Of the soft floorings, broadloom is more expensive to maintain because it must be replaced every 10 years compared to every 15 years for MCT. In a healthcare setting, the less disruption for remodeling equates to higher occupancy rates, perhaps making MCT the better choice in the soft flooring category. MCT has an additional advantage over broadloom, since carpet tiles subject to stains or contamination can be quickly and easily replaced with little to no disruption to occupants. ${ }^{[24]}$

Other factors that contribute to the quality of the indoor environment and quality of care, such as reducing noise and fatigue to increase safety and patient satisfaction have real world implications for occupant outcomes and the healthcare organization's efficacy. Retention and recruitment are factors where comfort and aesthetics contribute to the overall health of the organization. An organization's critical goals determine the weight of factors when establishing the best solution, beyond consideration for initial costs.

Equipment costs are considerable over the lifetime of the fa98 cility. Most LCCAs do not consider equipment replacement costs over time. As a financial consideration, evaluating the cost of equipment related to maintaining the floors provides insight to overall cost of ownership. At years 1 and 10, cumulative equipment costs are about 2.5 times more for hard and resilient flooring than for soft flooring; at year 25 the difference decreases slightly to just over 2 times; and at year 50, the difference in equipment costs returns to approximately 2.5 times more than soft flooring. These results are consistent with the higher overall cost for hard and resilient floor care machines (scrubbing and buffing machines), along with replacement costs for equipment and supplies. Soft floor care machines include vacuum cleaners, dry foam soil extractors, and hot water extractors, which were all found to be less expensive overall.

Maintenance plays a major role in the cost of ownership for flooring. Cleaning and care of hard and resilient floors were more intensive than soft flooring, increasing labor and chemical costs. When comparing maintenance protocols, resilient and hard surfaces were similar with exceptions for regrouting (some hard surfaces) and waxing (VCT); with some variation for how often procedures are recommended to be performed. For example, the cost for rubber increases from about $\$ 17$ per SF to maintain in year 1 to over $\$ 70$ per $\mathrm{SF}$ in year 25. This trend continues throughout the life of the building with O\&M costs for rubber and LVT exceeding all other flooring material options, while soft flooring remains the least expensive to maintain. When comparing O\&M costs for soft flooring, the expense of maintaining broadloom is comparable in year 1, but is increases two-fold that of MCT in year 10 due to broadloom's 10 year system service life compared to MCT's 15 year system service life. By year 25, the O\&M cost gap between these two material types lessens; however, it widens again at the building's end of life with the O\&M cost increase of approximately $60 \%$ per SF for broadloom compared to MCT, owing to the shorter service life and slightly more expensive initial and replacement costs of broadloom. For this LCCA, all flooring types were assumed to be in heavy traffic areas and replacement frequencies are based on industry standards, which may vary across facilities in the "real world". Variations on maintenance may give different results; however, these results may be used as a benchmarking tool. Quantifying the maintenance protocols and schedule provides clarity for comparing hard, resilient, and soft floor surfaces.

While industry standards for maintenance protocols suggest dust mopping smooth surfaces, the literature suggests that dust mopping should be replaced with vacuuming for better results. This would require additional cleaning equipment, which may have a financial impact on maintaining hard and 
resilient floors. One factor that drives maintenance is access. Healthcare facilities must consider how long a unit or part of a unit may be shut down for deep cleaning and refinishing. Other methods of sanitization may also be a factor in determining viable flooring choices for a particular use. For instance, the hydrogen peroxide mist and UV light units may provide a method of sanitizing for 3-diminsional surfaces, making MCT a more practical choice, given the other benefits of single tile replacement, acoustic properties, cushion underfoot, and aesthetics.

Cleaning protocols for addressing spills suggest immediate attention is required both for pedestrian safety (for smooth surfaces) and to protect the floor (soft surfaces). Because this LCCA has to be based on regular maintenance, which is quantifiable, and not on spontaneous floor care requirements, which are neither predictable, nor quantifiable, spill maintenance is not included. Spot cleaning is included and quantified as a weekly maintenance requirement. It may be practical to assume that spills are addressed in the weekly spot cleaning protocol addressed in this LCCA. Nonetheless, spill maintenance is not expected to have a significant impact on this LCCA.

It is important to look beyond the initial costs of any type of flooring. Maintenance (labor and cleaning materials) are significant. In a 250,000 SF heavy traffic facility, cumulative maintenance cost in the first year for hard and resilient flooring were on average $200 \%$ and $300 \%$, respectively, of the cost of installing these floors. For soft flooring the cumulative maintenance cost in the first year was, on average, $78 \%$ of the installation costs. These figures do not take into account future material replacements or equipment costs which will increase overall maintenance costs when compared to installation costs.

Flooring selections, maintenance schedules, and equipment purchases may vary across organizations and facilities. The results of this study provide a process for evaluating a facility's preferences and constraints to determine the long-term cost of ownership, supporting informed decisions.

\section{Conclusions}

A typical process for evaluation of flooring selection is to consider only the initial costs as the impact on the current budget. A systemic view considers the cost of ownership over the lifetime of the system and its impact on well-being, safety, durability, aesthetics, cleanliness, acoustics, and sustainability to gain a comprehensive view that contributes to the return on investment and effect on the triple bottom line - the social, environmental and financial impact on an organization. This study uses current financial data and national average cost data to project future value based on present value.

As a tool for decision-making, this study provides quantifiable information at every step of the LCCA process so that readers may use the data to inform their own decisions specific to their facility situation and flooring needs. While this study was concerned with healthcare facilities, the data was not specific to a single building type and may provide useful information for other market segments.

\subsection{Limitations}

Limitations were dictated largely from incongruent information provided by manufacturers about their products. Industry standards for warranties were inconsistent; and in some cases, system service life had to be determined based on other industry factors. Maintenance schedules were not clearly defined by manufacturers within flooring categories, perhaps due to differing geography, building typology, staffing budgets, or equipment availability. This study used average costs for floor maintenance equipment; however, costs and equipment functionality vary greatly. Projecting LCCA beyond 25 years may have limited value based on potential changes in the financial climate. Finally, cost data are based on aggregated data for $4^{\text {th }}$ quarter of 2014 , making this study time sensitive.

\subsection{Implications for practice and research}

- Maintenance costs are considerable, especially when compared to initial cost of flooring. The accumulative cost of cleaning and maintaining hard and resilient floors during the first year were $200 \%$ and $300 \%$ of initial cost respectively, compared to soft flooring (78\%).

- Equipment costs were significant over the life-cycle of the building; equipment for resilient and hard surfaces costs overall about 2.5 times more than for soft flooring.

- The results suggest that soft flooring is considerably more cost effective when evaluating initial cost, equipment cost, and O\&M costs over the life of the building.

- Of the soft flooring category, MCT has advantages over broadloom, including a longer system service life and the ability to replace a single carpet tile vs. having to cut out or replace a larger section in the event of a stain or contamination. These advantages decrease the potential of disrupting building operations.

\section{ACKNOWLEDGEMENTS}

The authors would like to acknowledge R. S. Means for providing the cost data for this study; and product manufacturers for providing access to protocols and recommendations for O\&M. 


\section{REFERENCES}

[1] Moussatche H, Languell-Urquhart J, Woodson C. Life Cycle Costs in Education: Operations \& Maintenance Considered. Facilities Design \& Management. 2000; 19(9): 20, 22.

[2] Freund LM. American College of Healthcare Executives Announces Top Issues Confronting Hospitals: 2014. Research Report on Hospital Studies. 2015. [cited March 10, 2015]. Available from: http: //www.ache.org/pubs/research/ceoissues.cfm

[3] Ulrich RS, Zimring C. The role of the physical environment in the hospital of the $21^{\text {st }}$ century: a once-in-a-lifetime opportunity. 2004

[4] Harris D, Detke L. The role of flooring as a design element affecting patient and healthcare worker safety. Health Environments Research \& Design. 2013; 6(3): 95-119. http://dx.doi.org/10.1177/1 93758671300600308

[5] Fuller S, Peterson S. Life-Cycle Costing Manual, B.a.F.R. Laboratory, Editor. U.S. Department of Energy: Gaithersburg, MD; 1995.

[6] Kirkham RJ, Boussabaine AH. Forecasting the residual service life of NHS hospital buildings: a stochastic approach. Construction Management \& Economics. 2005; 23(5): 521-529. http: //dx.doi.org/10.1080/0144619042000326729

[7] Kirk SJ, Dell'Isola A. Life Cycle Costing for Facilities. Norwell, MA: RSMeans; 2003.

[8] Fuller S. Life-Cycle Cost Analysis (LCCA). 2012. [cited 2012 February 6]. Available from: http://www.wbdg.org/resources/lcc a.php

[9] Jones G, White E, Ryan ET, et al. Investigation into the Ratio of Operating and Support Costs to Life-Cycle Costs for DoD Weapon Systems. Defense Acquisition Research Journal: A Publication of the Defense Acquisition University. 2014; 21(1): 441-464.

[10] Gransberg D, Molenaar K. Life-cycle cost award algorithms for design/build highway pavement projects. Journal of Infrastructure Systems. 2004; 10(4): 167. http://dx.doi.org/10.1061/(AS CE) $1076-0342$ (2004) $10: 4$ (167)

[11] Chan A, Keoleian G, Gabler E. Evaluation of Life-Cycle Cost Analysis Practices Used by the Michigan Department of Transportation. Journal of Transportation Engineering. 2008; 134(6): 236-245. http://dx.doi.org/10.1061/(ASCE) 0733-9 $47 \mathrm{X}(2008) 134: 6(236)$
[12] Thoft-Christensen P. Infrastructures and life-cycle cost-benefit analysis. Structure \& Infrastructure Engineering: Maintenance, Management, Life-Cycle Design \& Performance. 2012; 8(5): 507-516. http://dx.doi.org/10.1080/15732479.2010.539070

[13] Fuller S. Life-Cycle Cost Analysis (LCCA). 2010.

[14] Asiedu Y. Product life cycle cost analysis: state of the art review. International Journal of Production Research. 1998; 36(4): 883-908. http://dx.doi.org/10.1080/002075498193444

[15] Lozada-Figueroa C. Flooring materials-life-cycle costing for M.E. Rinker, Sr. School of Building Construction at the Unversity of Florida in Interior Design. University of Florida: Florida; 2004.

[16] Moussatche H, Languell J. Flooring materials-life-cycle costing for educational facilities. Facilities. 2001; 19(10): 333-343. http: //dx.doi.org/10.1108/02632770110399370

[17] FGI. Guidelines for Design and Construction of Hospitals and Outpatient Facilities. ASHE (American Society for Healthcare Engineering): Chicago; 2014.

[18] RS Means Cost Estimating, Reed Construction Data, Editor. Norwell: MA; 2014.

[19] Gorrée M, Buinée J, Huppes G, et al. Environmental Life Cycle Assessment of Linoleum. The Netherlands: Centre of Environmental Science; 2002.

[20] Tang Y, Edwards R, Gale A, et al. Feasibility study on the application of high power diode lasers in ceramic tile joint sealing. CIB W065/055 Commissions: Transformation through Construction. The National Terrazzo \& Mosaic Association, Inc.; Tile Council of North America, Inc.; Concrete Network; 2005.

[21] Weinhold VB. Interior Finish Materials for health Care Facilities. Springfield, IL: Thomas; 1988.

[22] Mearig T, Coffee N, Morgan M. Life Cycle Cost Analysis Handbook, Alaska Department of Education \& Early Development, Editor. State of Alaska: Juneau, Alaska; 1999.

[23] Damodaran A. Cost of Capital by Sector. nyu.edu: New York, NY; 2014.

[24] Sehulster L, Chinn RYW. Guidelines for environmental infection control in health-care facilities. Recommendations of CDC and the Healthcare Infection Control Practices Advisory Committee (HICPAC). American Society for Healthcare Engineering/American Hospital Association: United States; 2003. 79 p. PMid: 12836624. 